УДК 343.1

\title{
Л.А. Кротова
}

\section{СОУЧАСТИЕ В ПРИГОТОВЛЕНИИ К ПРЕСТУПЛЕНИЮ: НЕКОТОРЫЕ ВОПРОСЫ ТЕОРИИ И ПРАКТИКИ}

Статья посвящена вопросам уголовной ответственности за соучастие в приготовлении к преступлению. Рассматриваются теоретические основы правовой регламентации ответственности за приискание соучастников и сговор на совершение преступления, представленные сочетанием элементов акцессорной концепции (т.е. зависимости ответственности соучастников от преступной деятельности исполнителя) и концепции самостоятельной (личной) ответственности соучастников. Дана оценка сложившейся практики квалификации соучастия в неоконченном преступлении, ее оценка доктриной уголовного права. Выделены основные позиции относительно возможности соучастия в приготовлении преступлении, в том числе в ситуации «неудавшегося соучастия» и в случае добровольного отказа. В целях преодоления противоречивости правоприменительной практики предлагается конкретизировать в постановлении Пленума Верховного Суда РФ формулу квалификации деяния, совершенного соучастником приготовления к преступлению.

Ключевые слова: неоконченное преступление, приготовление к преступлению, соучастие в приготовлении, квалификация приискания соучастников и сговора на совершение преступления.

DOI: $10.35634 / 2412-9593-2021-31-2-257-264$

Приготовлением к преступлению признаются «приискание, изготовление или приспособление лицом средств или орудий совершения преступления, приискание соучастников преступления, сговор на совершение преступления либо иное умышленное создание условий для совершения преступления, если при этом преступление не было доведено до конца по независящим от этого лица обстоятельствам» (ч. 1 ст. 30 УК РФ). По сравнению с ранее действующим уголовным законодательством в УК РФ предусмотрены новые формы приготовительных действий. В их числе - «приискание соучастников преступления, сговор на совершение преступления».

Указанные деяния тесно взаимосвязаны, но в то же время каждое из них имеет самостоятельное уголовно-правовое значение. Приискание соучастников представляет собой действие, направленное на склонение (вовлечение) других лиц к совершению преступления или участию в нем. В то время как сговор на совершение преступления есть соглашение о совершении преступления, конечный результат, которым может закончиться деятельность по приисканию соучастников.

Таким образом, самостоятельность приискания соучастия проявляется и в том, что оно может быть прервано, не приводя к формированию сговора.

Доктринальное толкование данной формы приготовления к преступлению, предлагаемое в научной литературе разными авторами, различается скорее не содержанием, а своей редакцией. Подчеркивается, что приискание соучастников в больше степени характерно для организатора преступления. Оно состоит в завязывании знакомств с потенциальными соучастниками, побуждении их к участию в конкретном преступлении, обсуждении роли каждого и т.п. [1. С.19].

А.Я. был признан организатором убийства, совершенного по найму, т. е. преступления, предусмотренного ч. 3 ст. 33, ч. 1 ст. 30, п. «з» ч. 2 ст. 105 УК РФ. А.Я. предложил Б.В. совершить убийство А.И.Э. за денежное вознаграждение, предоставил тому сведения о личности А.И.Э., данные о местах его жительства и работы, марке его автомобиля и государственном регистрационном номере, фотографию последнего, передал денежные средства для приобретения автомашины, которую предполагалось использовать при совершении убийства, также им совместно с Б.В. был разработан план совершения указанного преступления [2].

Другие отмечают, что приискание соучастников предполагает их нахождение и вербовку, осуществляемую путем уговоров, шантажа, подкупа и т. д. [3]. В таком понимании эти действия характерны для подстрекателя. По указанному выше уголовному делу А.Э. был осужден за подстрекательство и пособничество в приготовлении убийства, т. е. преступления, предусмотренного ч. 4,5 ст. 33 , ч. 1 ст. 30. п. «з» ч. 2 ст. 105 УК РФ. А.Э., решив совершить убийство А.И.Э., предложил А.Я. организовать совершение данного преступления, предоставив в его распоряжение соответствующую ин- 
формацию о местожительстве, работы, автомобиле А.И.Э., передал фотографию последнего, для предъявления ее в дальнейшем лицам, которые должны были совершить убийство А.И.Э.

По тому же делу действия Б.В. по приобретению автомобиля, на котором он приезжал к месту жительства потерпевшего, были признаны пособничеством в приготовлении убийства.

Приискание соучастников (как и иные приготовительные действия) влекут уголовно-правовые последствия лишь в тех случаях, когда данная деятельность направлена на совершение конкретных тяжких либо особо тяжких преступлений.

Законодательное закрепление сговора как самостоятельной формы приготовления неоднозначно оценивается доктриной уголовного права. Так, А. Мондохонов полагает, что начало совершения преступления связано с деянием, а не с умыслом, а потому признание сговора на совершение преступления в качестве составляющей приготовления к преступлению противоречит постулатам законности и справедливости, в связи с чем подлежит исключению из ч. 1 ст. 30 УК [4. С. 51], поскольку возможны ситуации, когда сговор состоялся, однако не получил реализации в конкретных действиях. Далее автором моделируется подобная ситуация. Так, двое, будучи в состоянии алкогольного опьянения договорились совершить кражу в одном из домов. Один из них (А.) в последний момент остался на улице. По причине сильного опьянения он был не в состоянии проникнуть в дом. Второй совершил кражу, полагая, что действует совместно с А.

Другие, соглашаясь с приведенными выше доводами, кроме того, отождествляют сговор на совершение преступления с обнаружением умысла. При этом отмечается, что участники сговора только договариваются, не совершая при этом никаких действий, то есть возникает намерение совершить преступление [1. С. 19]. А поскольку умысел по действующему законодательству уголовно не наказуем, следует, по их мнению, исключить данное положение из законодательного определения приготовления к преступлению.

Приведенные выше доводы не представляются достаточно убедительными. Обнаружение и формирование умысла не являются стадией совершения преступления, поскольку формирование преступного умысла представляет собой, прежде всего, внутренний психологический процесс, протекающий в сознании ..., но не проявляющийся в объективной действительности действиями, направленными на совершение преступления [5]. Будучи самостоятельной формой приготовления, сговор имеет уголовно-правовое значение не только как некий состоявшийся (несостоявшийся) результат будущего (желаемого) взаимодействия нескольких лиц, лишь как получение согласия участвовать в совершении преступления. Содержание сговора, установленное в ходе производства по делу, позволяет дать правовую оценку планируемой преступной деятельности, решить вопрос о наличии (отсутствии) основания уголовной ответственности. Именно сговор отражает общее намерение совершить преступление определенным способом, в определенном размере, в отношении определенного лица, определенным орудием и т. п., то есть охватывает собой признаки, которые влияют на квалификацию содеянного [6], фактически представляет собой начальный этап планирования преступления.

В юридической литературе предлагается определение сговора как приготовления к преступлению. В качестве признаков выделяют: «наличие двух или более лиц, совместный умысел и согласие на совершение преступления или участие в нем, цель совершения тяжкого или особо тяжкого преступления (или преступлений), готовность участников сговора к исполнению преступления или участию в нем» [7. С. 65].

Вряд ли данную попытку можно признать удачной. С одной стороны, указные признаки воспроизводят содержание ст. 32 УК РФ, (наличие двух или более лиц, совместный умысел и согласие на совершение преступления или участие в нем), т. е. не раскрывают особенностей этого явления применительно к стадии приготовления. С другой стороны, неясно, чем отличается согласие совершить преступление и готовность к его исполнению, коль скоро, каждому из них предлагается придавать значение самостоятельного признака. Фактически они означают одно и тоже. Указание на цель совершения тяжкого или особо тяжкого преступления также характеризует приготовительную деятельность в целом, а не только сговор как ее конкретную форму.

Предложения о необходимости разграничения сговора как элемент соучастия и «сговорприготовление», вряд ли можно признать конструктивными, а доводы - убедительными. Ибо, с одной стороны, утверждается, что «состоявшийся, но прерванный до начала покушения сговор ... и есть сговор, который не относится к институту соучастия, не представляет самостоятельного преступления, но образует приготовление» [7. С. 66], а с другой стороны, содержание «сговора-приготовления» 
определяется на основе признаков, предусмотренных ст. 32 УК РФ. Понятие и содержание сговора на совершение преступления вряд ли могут иметь существенные отличия в зависимости от правового института, в рамках которого законодатель регулирует соответствующие отношения.

Признание самостоятельности приискания соучастников и сговора на совершение преступления как форм приготовительных к нему действий не означает абсолютного отрицания их единства. Для констатации наличия соучастия в приготовлении преступления недостаточно установить только действия по приисканию исполнителя, других соучастников. Лишь состоявшийся сговор, в ходе которого была достигнута договоренность относительно конкретных обстоятельств совершения конкретного преступления (участия в нем), вместе с предшествующими сговору действиями по приисканию соучастников дает основания для принятия соответствующего решения.

Наличие в уголовном законе таких форм приготовления, как приискание соучастников преступления, сговор на совершение преступления дает основание рассматривать в качестве нормативной основы института соучастия и ряд правовых положений гл. 6 УК РФ и говорить о возможности соучастия и на этом этапе развития преступной деятельности. Постановка данного вопроса во многом обусловлена своеобразием правового регулирования института соучастия в современном российском уголовном законодательстве, теоретической основой которой является «сочетание элементов как акцессорной концепции (т. е. зависимости ответственности соучастников от преступной деятельности исполнителя), так и концепции самостоятельной (личной) ответственности соучастников» [8]. Это обстоятельство позволило некоторым авторам констатировать тот факт, что в УК РФ «нормы о соучастии в преступлении являются «эклектичными» по своему содержанию» [9], что во многом и предопределяет наличие противоречий в правоприменительной практике и, как следствие, дискуссии в доктрине уголовного права.

В уголовно-правовой литературе относительно вопроса о возможности соучастия на этапе приготовлении к преступлению определились три основные позиции.

Согласно первой из них, опирающейся на положения акцессорной теории, соучастие в неоконченном преступлении исключается, тем более исключается на этапе приготовления к преступлению. Основные положения акцессорной теории соучастия [10] можно определить следующим образом: без исполнителя нет соучастия, поскольку именно его действия (состав преступления, им выполненный) является основанием ответственности соучастников (организатора, подстрекателя, пособника); уголовная ответственность за соучастие в преступлении наступает лишь в случае, если исполнитель начал выполнять объективную сторону состава преступления.

Представляется, что именно постулаты данной концепции составляют теоретическую основу выводов М.В. Рассказовой, полагающей, что «если состоявшийся сговор не перерос в стадию покушения на преступления, то он не может рассматриваться с позиций института соучастия в преступлении, поскольку здесь нет требуемого для соучастия исполнения преступления... Сговор, который не относится к институту соучастия, не составляет самостоятельного преступления, но образует собой приготовление» [7. С. 66]. Данный подход к уголовно-правовой оценке приготовительных действий, совершаемых несколькими лицами, поддерживает А.С. Некоз, утверждая, что в ситуации, когда действия исполнителя представляют собой только приготовление к преступлению, иные соучастники не могут нести ответственность за соучастие в приготовлении [11. С. 20].

Вторая позиция относительно возможности соучастия в неоконченном преступлении (приготовлении и покушении) сформировалась на основе концепции самостоятельной (личной) ответственности соучастников. Ее сторонники, не отрицая значимости содеянного исполнителем, реализующим общий совместный умысел на совершение преступления, полагают тем не менее, что каждый из соучастников своими действиями, посягающими на охраняемые уголовным законом общественные отношения, «создает основание своей уголовной ответственности» [12. С. 587]. Таким образом, «соучастие при неоконченном преступлении будет иметь место во всех случаях совместной деятельности двух или более лиц, заключающей в себе действия по приготовлению к преступлению, даже если здесь нет фигуры исполнителя. Тогда каждый из соучастников будет нести уголовную ответственность по соответствующей статье Особенной части со ссылкой на ст. 30 и ст. 33 Общей части УК PФ» [13. C. 26].

Согласно третьей позиции оценка деяния, выражающегося в приискании соучастников и сговоре на совершение преступления, зависит от причины, в силу которой преступление не доведено до конца. Соучастие в приготовлении имеет место, если преступный умысел не был реализован по не 
зависящим от лица обстоятельствам. В этом случае при квалификации делается ссылка одновременно на ч. 1 ст. 30 (или ч. 3 ст. 30) и соответствующую часть ст. 33 УК РФ, что позволяет «отразить конкретную роль соучастника в совершении неоконченного преступления» [8; 14. С.9].

Именно по такому пути в правовой оценке неоконченного преступления на стадии приготовления, как максимально соответствующему уголовному законодательству, идет судебная практика.

Сторонники рассматриваемой позиции, оценивая именно такую практику квалификации соучастия в приготовлении преступления как соответствующую букве закона, считают необходимым закрепить данное правило в ч. 5 ст.34 УК РФ. Так, В. Питецкий предлагает изложить данную статью в следующей редакции: «В случае недоведения исполнителем преступления до конца по независящим от него обстоятельствам остальные соучастники несут уголовную ответственность за приготовление к преступлению или за покушение на преступление со ссылкой на соответствующую часть ст. 33 настоящего Кодекса» [15. С.51]. Поскольку указание на квалификацию преступления «со ссылкой на статью 33 настоящего Кодекса» содержится в ч. 3 ст. 34 УК РФ, более удачным представляется иной вариант формулировки данной статьи: «Остальные соучастники несут уголовную ответственность за соучастие в приготовлении к преступлению или покушении на преступление по правилам части третьей настоящей статьи» [16. С.272].

Но реализация преступного умысла на стадии приготовления может быть прервана, в том числе, и по обстоятельствам, от лица зависящим. Речь идет о неудавшемся соучастии, когда деятельность подстрекателя (организатора, пособника) оказывается безрезультатной, так как исполнитель не совершает преступления.

В теории уголовного права нет единого понимания неудавшегося соучастия. Как неудавшееся соучастие рассматриваются либо лишь те случаи, когда подстрекателю «не удалось склонить другое лицо к совершению преступления» [12. С.631], либо дается более широкое толкование, согласно которому в этом качестве следует рассматривать и ситуации, когда, дав согласие на участие в совершении преступления (возможно, совершив часть приготовительных действий), лицо впоследствии добровольно отказывается от доведения его до конца [17. С.11; 14. С.11].

Несмотря на поддержку последнего из указанных выше мнений многими авторами, тем не менее, представляется, что добровольный отказ имеет иную правовую природу, отличную от неудавшегося соучастия как такового. Согласно ч. 1 ст. 31 УК РФ, добровольным отказом от преступления признается прекращение лицом приготовления к преступлению, то есть прерывание совершения действий, указанных в ч. 1 ст.30 УК РФ. Но прекратить можно лишь то, что уже началось. Начавшаяся, но прерванная после состоявшегося сговора подготовительная к преступлению деятельность характеризуется наличием нескольких лиц, определенной совместностью их действий, объединенных единством умысла, то есть признаками соучастия, предусмотренными ст. 32 УК РФ. Наличие указанных признаков и обусловливает различие в юридической оценке неудавшегося соучастия и добровольного отказа от преступления.

Уголовно-правовая оценка неудавшегося соучастия в буквальном смысле слова (когда подстрекателю не удалось склонить другое лицо к совершению преступления) в научной литературе является общепризнанной [18. С.47]. Содеянное квалифицируется по правилам неоконченного преступления со ссылкой на ч. 1 ст. 30 УК РФ. Примером может служить уголовное дело по обвинению Е. в совершении преступления, предусмотренного ч. 1 ст. 30, п. «3» ч. 2 ст. 105 УК РФ. Е. обратился к знакомому ему ранее В. с предложением приискать исполнителя убийства А., пообещав денежное вознаграждение. В., не желая принимать участие в совершении преступления, сообщил в правоохранительные органы о предложении, поступившем от Е., оказать содействие в организации убийства. Затем В., действуя в рамках оперативно-розыскного мероприятия, сообщил Е., что нашел исполнителя преступления. Е. передал В. точную информацию об А. (адрес фактического проживания, контактные телефоны, данные об автомобиле А., фотографию последнего). Свой умысел на лишение жизни А. по найму Е. не смог довести до конца по не зависящим от него обстоятельствам, поскольку действия были пресечены сотрудниками правоохранительных органов [19].

Данное судебное решение является типичным примером неудавшегося соучастия, когда инициатору преступления не удается склонить к его совершению иное лицо. Сговор не состоялся, и вменение соучастия в преступлении исключается. 
Иное дело, когда речь идет о добровольном отказе от совершения преступления на стадии приготовления, когда лицо дает согласие на участие в преступлении (совершает определенные приготовительные действия), а затем по каким-либо причинам отказывается доводить его до конца.

По приговору Нижегородского областного суда М.Е. признана виновной в совершении преступления, предусмотренного ч. 3 ст. 33 ч. 1 ст. 30, п. «з» ч. 2 ст. 105 УК РФ. М.Е. организовала приготовление к убийству Б.В.В. по найму, не доведенное до конца по независящим от нее обстоятельствам.

М.Е. предложила А.А.С. совершить убийство за денежное вознаграждение, который с ее согласия и подыскал соисполнителя указанного преступления Х.Р.А. После чего М.Е. передала в распоряжение А.А.С. и Х.Р.А. фотографии Б.В.В., ключи от двери в его подъезд, сведения о его месте жительства, распорядке его дня, месте работы, ключи от двери подъезда.

Б.В.В. оказался знакомым Х.Р.А. и, не желая принимать участия в убийстве, обратился в правоохранительные органы и стал добровольно принимать участие в оперативно-разыскных мероприятиях в целях выявления и пресечения преступления. В ходе проведения оперативно-разыскных мероприятий М.Е. были предоставлены «доказательства» совершенного преступления.

Таким образом, довести убийство Б.В.В. по найму до конца М.Е. не удалось по обстоятельствам, от нее независящим, по причине пресечения ее деятельности сотрудниками правоохранительной деятельности [20]. Апелляционным судом приговор оставлен без изменения [21].

Сторонники толкования добровольного отказа как неудавшегося соучастия исходя из акцессорной теории считают, что, поскольку в деянии лица, добровольно отказавшегося от доведения преступления до конца, нет состава преступления..., различные формы содействия этому деянию (склонение к совершению преступления, его организацию и т.п.) следует расценивать в качестве неудавшегося соучастия (нет исполнителя - нет и соучастия) в преступлении и квалифицировать их как приготовление к соответствующему преступлению [8]. Принимая во внимание высказанное в уголовно-правовой науке мнение, что приготовительные действия, совершенные до добровольного отказа, все же содержат признаки состава преступления [22. С. 42], К.В. Ображиев приводит еще один довод - незавершенность по независящим от лица обстоятельствам [8].

Аргументируя свою позицию, автор обращается к следующему высказанному в научной литературе теоретическому положению: «Если начатое деяние было прекращено по обстоятельствам, зависящим от лица, его совершившего, то содеянное не образует состава преступления. Состава оконченного преступления нет в силу того, что действия не доведены до конца (то есть не содержат всех признаков состава преступления, предусмотренного в статях Особенной части), а состава неоконченного преступления нет потому, что эти действия прекращены по обстоятельствам, зависящим от субъекта» [23. С. 228].

Обозначенная проблематика настоящей статьи не предполагает необходимости всесторонней оценки приведенного выше мнения. Но, тем не менее, исходя из контекста указанного научного исследования следует отметить, что данное высказывание сформулировано автором как положение общего порядка, не имеющее непосредственного отношения к совместной преступной деятельности нескольких лиц. Речь идет о добровольном отказе_от доведения преступления до конца лицом, совершающим его без какого-либо организационного и иного содействия. Именно о том аспекте практики применения ст. 31 УК РФ, относительно оценки которого в доктрине уголовного права нет существенных разногласий.

Говоря о соучастии в приготовлении преступления при добровольном отказе, когда имеет место организаторское или иное содействие других лиц, следует отметить, «злая воля исчезает, прекращается» [24. С. 315] у предполагаемого исполнителя, но сохраняется у организатора, подстрекателя, пособника. В то же время уровень общественной опасности действий последних, безусловно, выше, чем в случаях осуществления лицом приготовления к преступлению лишь собственными усилиями, без привлечения иных лиц. Общественная опасность такого деяния определяется одновременно как созданием условий для совершения конкретного преступления, так и фактом вовлечения в преступную деятельность (склонению к его совершению) иного потенциального участника (участников). Последнее обстоятельство также должно получить правовую оценку, что возможно лишь в рамках института соучастия.

В качестве одной из тенденций российской уголовной политики последних десятилетий следует отметить криминализацию отдельных видов соучастия (ст. 205.1, ч. 1.1 ст. 212, ч. 1.1 ст. 281.1, ч. 1.1 ст. 282.2 УК РФ). 
Несмотря на критическое отношение к появлению все новых и новых специальных составов [25] данная политика тем не менее свидетельствует о заинтересованности законодателя в разработке правовых механизмов учета общественной опасности вовлечения в преступную деятельность (склонению к его совершению). И, кроме того, служит дополнительным аргументом в пользу правоприменительной практики квалификации по правилам соучастия организаторского, подстрекательского и пособнического содействия в приготовлении преступления при добровольном отказе предполагаемого исполнителя, то есть со ссылкой на ст. 33 УК РФ.

Обобщение судебной практики, кроме того, показывает отсутствие единой формулы квалификации соучастия в приготовлении к преступлению: либо сначала делается ссылка на ст. 33, а затем на ч. 1 ст. 30; либо, наоборот, сначала на ч. 1 ст. 30, а затем на ст. 33 УК РФ.

Так, признавая наличие в действиях М. состава организации убийства С. по найму (разработка плана, поиски исполнителя - А., передача денег А. за его совершение, но при этом недоведение его до конца в связи с тем, что потерпевший С. уговорил А., сообщившему о ему намерениях М., обратиться в правоохранительные органы), Верховный Суд Российской Федерации квалифицировал содеянное М. по ч. 1 ст. 30, ч. 2 ст. 33, п. «з» ч. 2 ст. 105 УК РФ [26]. Неоднозначность правовой квалификации рассматриваемой приготовительной деятельности получила негативную оценку в уголовнопроцессуальной литературе, ибо порядок записи формулы квалификации (сначала ссылка на ст. 33, а затем на ст. 30 УК), далеко не всегда соблюдающийся в судебной практике, имеет принципиальное значение, поскольку отражает факт того, что имело место именно соучастие в неоконченном преступлении исполнителя, ... а не приготовление к соучастию или покушение на соучастие... [12. С. 9].

В то же время следует отметить, что, несмотря на различную последовательность ссылок на ст. 30 и ст. 33 УК РФ в судебных решениях, и в том, и в другом случае юридическая формула обвинения преимущественно начинается именно с описания роли лица, участвовавшего в приготовлении преступления. Так, приговором Кочубеевского районного суда Ставропольского края Ф.С. признан виновным в организации приготовления к убийству, то есть умышленному причинению смерти другому человеку, совершенному по найму. Его действия были квалифицированы по ч. 1 ст. 30 , ч. 3 ст. 33 п. «з» ч. 2 ст. 105 УК РФ [27].

По другому уголовному делу суд, признавая Т.Г. виновным в организации приготовления к убийству двух лиц по найму, при этом преступление не было доведено до конца по независящим от этого лица обстоятельствам [28], при квалификации его действия избрал иной порядок ссылки на статьи Общей части Уголовного кодекса, а именно: по ч. 3 ст. 33 ч. 1 ст. 30 п. «з» ч. 2 ст. 105 УК РФ.

Приведенные фрагменты судебных решений дают основания для того, чтобы сделать следующий вывод: начинать запись формулы квалификации следует с указания на соответствующую часть ст. 33, а затем - на ч. 1 ст. 30 УК РФ.

В уголовно-правовой литературе отмечается, что противоречивость правоприменительной практики во многом обусловлена отсутствием в уголовном законе и постановлениях Пленума Верховного Суда РФ конкретизации формулы квалификации деяний соучастниками неоконченного преступления [8]. Принимая во внимание, что рассматриваемые вопросы возникают по большей части в процессе производства по делам, возбужденным в связи с подготовкой к совершению преступлений, предусмотренных ст. 105 УК РФ, представляется целесообразным дополнить постановление Пленума Верховного Суда РФ № 1 от 27 января 1999 г (ред. от 3 марта 2015 г. № 9):

- во-первых, пунктом, разъясняющим, что квалификация организаторского, подстрекательского и пособнического содействия в приготовлении убийства при добровольном отказе предполагаемого исполнителя производится по правилам соучастия, то есть со ссылкой на соответствующую часть ст. 33 УК РФ;

- во-вторых, пунктом, разъясняющим, что при квалификации организаторского, подстрекательского и пособнического содействия в приготовлении убийства содеянное следует квалифицировать по соответствующей части ст. 33 и ч. 1 ст. 30 УК РФ.

\section{СПИСОК ЛИТЕРАТУРЫ}

1. Чернокозинская С.В. Приготовление к преступлению: понятие, основания и признаки криминализации, влияние на квалификацию преступления и наказание: автореф. дис. ... канд. юрид. наук. Саратов, 2005.

2. Приговор Волгоградского областного суда от 14 февраля 2014 г. по делу № 2-1/2014 // СПС «Консультант Плюс». 
3. Уголовное право России. Общая и Особенная части: учебник /отв. ред. Ю.В. Грачева, А.И. Чучаев. М.: Контракт, 2017 // СПС «КонсультантПлюс».

4. Мондохонов А. Сговор - не основание для уголовной ответственности // Российская юстиция. 2002. № 12.

5. Карпова Н.А. Неоконченная преступная деятельность (понятие и проблемы квалификации): учебное пособие. М.: Юриспруденция, 2017 // СПС «КонсультантПлюс».

6. Комментарий к Уголовному кодексу Российской Федерации: в 4 т. Т.1:Общая часть (постатейный) / отв. ред. В.М. Лебедев. М.: Юрайт, 2017 // СПС «КонсультантПлюс».

7. Рассказова М.В. Сговор как форма приготовления к преступлению // Вестник Краснодар. ун-та МВД России. 2016. № 1 (31).

8. Ображиев К.В. Влияние результатов уголовно-правовой оценки действия (бездействия) исполнителя на квалификацию деяний иных соучастников преступления // Законность. 2016. № 8 // СПС «КонсультантПлюс».

9. Трухин A.M. От акцессорной концепции к самостоятельной концепции соучастников преступления. URL: http://www.rusnauka.com/17 AND 2011/Pravo/11 89725.doc.htm.

10. Ковалев М.И. Соучастие в преступлении: монография. Екатеринбург, 1999.

11. Некоз А.С. Уголовная ответственность за подстрекательство к преступлению: автореф. дис. ... канд. юрид. наук. М., 2019.

12. Курс советского уголовного права. Т. 1: Часть Общая. Л.: Изд-во ЛГУ, 1968.

13. Кухтина В.Т., Беляева И.М. Вопросы квалификации при «неудавшемся» соучастии» // Вестник ЮжноУральского гос. ун-та. Сер.: Право. 2017. Т.17, № 4.

14. Шарапов Р.Д. Соучастие в неоконченном преступлении и «неудавшееся соучастие» // Юридическая наука и правоохранительная деятельность. 2018. № 1 (43).

15. Питецкий В. Неудавшееся соучастие в преступлении // Российская юстиция. 2003. № 4.

16. Актуальные проблемы уголовного права: учебник для магистрантов / отв. ред. И.А. Подройкина. М.: Проспект, 2018.

17. Семернева Н.К. Квалификация преступлений (части Общая и Особенная): науч.-практ. пособие. Екатеринбург, 2008.

18. Плаксина Т. Неудавшееся подстрекательство // Уголовное право. 2011. № 4.

19. Приговор Новосибирского областного суда от 14 ноября 2013 г. по делу № 2-56/13; Апелляционное определение Судебной коллегии по уголовным делам Верховного Суда РФ от 8 апреля 2014 г. № 67-АПУ14-18 // СПС «КонсультантПлюс».

20. Приговор Нижегородского областного суда от 19 января 2018 г. по делу № 2-3/2018 // СПС «Консультант Плюс».

21. Апелляционное определение Судебной коллегии по уголовным делам Верховного Суда РФ от 27 марта 2018 г. № 9-АПУ18-3 // СПС «КонсультантПлюс».

22. Звечаровский И.Э. Добровольный отказ от доведения преступления до конца. СПб.: Юрид. центр Пресс, 2008.

23. Щепельков В.Ф. Уголовный закон: преодоление противоречий и неполноты. М.: Юрлитинформ, 2003.

24. Таганцев Н.С. Русское уголовное право: лекции. Часть Общая: в 2 т. Т.1. М.: Наука, 1994.

25. Рарог А.И. Уголовно-правовые позиции законодателя и правоприменителя // «Lex russica». 2016. № 11 // СПС «КонсультантПлюс».

26. Кассационное определение от 16 ноября 2004 г. по делу № 5-о04-215 // СПС «КонсультантПлюс».

27. Апелляционное определение Ставропольского краевого суда от 12 февраля 2018 г. по делу № 22-282/2018. Приговор Верховного суда Республики Дагестан от 30 июня 2009 г. по делу № 2-21/2009 // СПС «КонсультантПлюс».

28. Апелляционное определение Верховного суда Удмуртской Республики от 13 января 2015 г. по делу № 22/2015 //СПС «КонсультантПлюс».

Кротова Любовь Анатольевна, кандидат юридических наук, доцент

кафедры уголовного права и криминологии

ФГБОУ ВО «Удмуртский государственный университет»

426034, Россия, г. Ижевск, ул. Университетская, 1 (корп. 4)

E-mail: Krotova_LA@mail.ru 


\section{L.A. Krotova}

COMPLISITY IN PREPARATION OF CRIME: SOME QUESTIONS OF THEORY AND PRACTICE

DOI: $10.35634 / 2412-9593-2021-31-2-257-264$

The article is devoted to the issues of criminal liability for complicity in preparation for a crime. Theoretical foundations of the legal regulation of liability for seeking accomplices of a crime and collusion of a crime, the existing judicial practice and a critical appraisal thereof by a criminal law science is discussed. The main positions regarding the possibility of complicity in the preparation of a crime, including in the situation of "failed complicity" and in the case of voluntary refusal, are highlighted. It is proposed to concretize in the decision of the Plenum of the Supreme Court of the Russian Federation the formula for qualifying an act committed by an accomplice in the preparation for a crime.

Keywords: uncompleted crime, preparation for a crime, complicity in the preparation for a crime, seeking accomplices of a crime, collusion of a crime, qualification for seeking accomplices of a crime and collusion of a crime.

Received 11.02.2021

Krotova L.A., Candidate of Law, Associate Professor at Department of criminal law and criminology Udmurt State University

Universitetskaya st., 1/4, Izhevsk, Russia, 426034

E-mail: Krotova_LA@mail.ru 